\title{
A DUPLA VERDADE NA ESTÉTICA DE HANSLICK'
}

\section{THE DOUBLE TRUTH IN HANSLICK'S AESTHETICS}

\author{
Maurizio Giani \\ maurizio.giani@unibo.it \\ Tradução: Rafael Alexandre da Silva \\ rafael.fortaleza@hotmail.com
}

\section{Resumo}

texto II Bello musicale, de Eduard Hanslick, que é referência, no que tange à estética musical como um todo, até os dias atuais, possui contradições de pensamento, algumas das quais revisitadas pelo seu autor no curso da vida bibliográfica de sua obra, mas que, ao invés de serem de fato problemáticas de um ponto de vista teórico, transparecem uma dupla verdade no pensamento de Hanslick. Ao se analisar os textos $e$ as modificações feitas pelo autor, bem como a origem dos conceitos utilizados por Hanslick em seu trabalho, partindo de uma abordagem metalinguística dos conceitos por ele utilizados, e observando-se as terminologias, metáforas e analogias por ele empregadas, é possivel notar a evolução de duas linhas de pensamento que coexistem: uma de caráter analítico que, de fato, baseia o célebre formalismo hanslickiano, e que faz coincidir o plano dos conteúdos musicais com o plano gramático-sintático da música, restando, assim, a "pura forma"; e a outra insere, por outro lado, a estética musical de Hanslick em uma tradição de atribuição de conteúdos musicais por meio de analogias e metáforas já

I No original, La doppia verita nell'estetica di Hanslick. Ensaio publicado no Anuario di Latinità e Medioevo da Universidade de Salerno (Itália). Referências do original: CIANI, Maurizio. La doppia verita nell'estetica di Hanslick. SCHOLA SALERNITANA, Salerno, Anal de Congresso, Salerno: Ripostes, 200 1, p. 199-221. Contudo, esta tradução se baseia em uma revisão especialmente feita pelo autor para a versão em português, em outubro de 2017. Além disso, a fim de que a formatação se enquadrasse nas exigências das diretrizes para publicações da Revista da Tulha, os números das notas sofreram alteração em relação ao original, bem como seu conteúdo, tendo sido conservadas aquelas que se referem a comentários do autor, e excluídas aquelas que funcionavam no original como bibliografia. Ademais, o resumo/abstract aqui apresentado foi feito por mim, tradutor, haja vista que no original não constava nenhum resumo/abstract, tanto na versão do ano 2000 quanto na revisão feita pelo prof. Giani (Nota do Tradutor). 
incorporadas pela própria teoria musical enquanto única possibilidade de se falar sobre música, haja vista a necessidade de se tratar de uma linguagem (a música) através de outra (a língua). Por fim, essa dualidade, aparentemente contraditória, pode ser explicada também através do conceito de semântica atribuida por direito, desenvolvido por Gyorg Lukács, no qual, devido à natureza puramente sonora da música, tal dualidade se dissolveria na necessidade de tratá-la, por direito de uso, ao mesmo tempo, tanto de um ponto de vista formalista quanto conteudista, donde os significados se dão por atribuições de sentidos que estão além da própria música, e que são necessários à reflexão estética sobre música.

Palavras-chave: estética musical; Hanslick; crítica; semântica atribuida por direito.

\section{Abstract}

The text II Bello musicale, by Eduard Hanslick, which is reference regarding musical aesthetics in general until nowadays, has contradictions in its thoughts, some of those were reviewed by its author in the course of the bibliographic life of his work, but, instead of being in fact problematic from a theoretical point of view, that makes appear a double truth in Hanslick's thoughts. On analyzing texts and modifications done by the author, as well as the origin of concepts used by Hanslick in his work, from a metalinguistic approach of the concepts, and observing terminologies, metaphors and analogies used by him, it is possible to notice the evolution of two lines of thinking that coexist: one with analytical characteristics that, in fact, bases the well-known hanslickian formalism, and which makes the musical content level match with the grammatic-syntatical level of music, remaining, thus, "pure form"; and the other inserts, on the other hand, the musical aesthetics of Hanslick in a tradition of musical content attribution through analogies and metaphors already integrated by musical theory itself as only possibility of speaking of music, for it is necessary to deal with one language (music) through another (language itself). Finally, that duality, apparently contradictory, may also be explained through the concept of attributed semantic by right, developed by Gyorg Lukács, in which, due the purely sound nature of music, that duality would be dissolved in the need of treating it, by right of its usage, at the same time as much from a formalist point of view as from a contentistic, from which 
meanings are given by attribution of senses that are beyond music itself, and which are necessary to aesthetic reflection on music.

by right.

Keywords: musical aesthetics; Hanslick; critic; attributed semantic

\section{Problemas textuais}

A sorte de II Belo musicale ${ }^{2}$ de Eduard Hanslick nos quase cento e cinquenta anos transcorridos desde o lançamento de sua primeira edição ${ }^{3}$ é fundada na própria coisa. A batalha de Hanslick contra a ideia de que a essência da música consistia na representação dos sentimentos, e não somente a sua promoção de uma estética polarizada sobre os elementos formais da obra musical, são instâncias que a reflexão do século XX - privilegiando os dados exatos a respeito da emotividade e da forma "objetiva" da partitura em relação à sua veste sonora - tomou, em larga medida, para si. Basta considerar a difusão atual, na Europa e sobretudo nos Estados Unidos, das metodologias analiticas de Heinrich Schenker e de seus alunos, que perseguem o ideal de uma abordagem científica às composições musicais livres de sugestões impressivas ou literárias, para compreender quanta simpatia ainda pode suscitar o volume, do qual as teses continuam a ser retiradas com a tranquila adesão que se reserva comumente a ensaios recentes ${ }^{4}$. E também este evergreen da estética musical é, em certos aspectos, um objeto desconhecido. Salvo alguns estudos especializados, no século recentemente terminado, ele é lido e citado de modo muitas vezes exclusivo, segundo as volumosas reimpressões da décima edição (1902), a última revista pelo autor, sobre a qual vem também produzida a tradução italiana5. Mas, o volume de 1902 era o ponto de chegada de uma trama infinita de reescritas, postergadas no curso de cerca de meio século; e somente há pouco mais de uma década é possivel

2 Mantive o nome do livro de Hanslick em italiano a fim de evitar confusões, pois è assim que o prof. Giani se refere a ele sem seu texto (N. T.).

3 HANSLICK, Eduard. Vom Musikalisch-Schönen. Ein Beitrag zur Revision der Aesthetik der Tonkinst. Leipzig: Weigel, 1854 [reimpresso em Darmstadt: Wissenschaftliche Buchgedellschaft, 1991 ]. No trabalho original, esta nota corresponderia à primeira (N. T.).

4 Cf., por último, ROSSI, 2000, p. 57-96: 88-89.

5 DONA, $1945[1971]$. 
vizualizar o seu vir-a-ser com a calma que sua delicada história textual demanda6.

Empreender um trabalho de exegese fazendo referencia somente à última edição, sem ter em conta o todo do arco de desenvolvimento do pensamento de Hanslick, pode trazer o risco de más interpretações? Quem, como Peter Kivy , se obstina ainda a afirmar, contra o próprio Hanslick, que a sua teoria negaria a capacidade da música de suscitar sentimentos, deveria talvez refletir sobre uma passagem do prefácio à segunda edição -- ressurgida graças a Strauss --, no qual vem afirmado que "o sentimento deve residir na música, como o perfume na rosa, mas não apoiada sobre ela, como a máscara sobre o rosto do ator"9. Ali é obscurecida, além disso, uma tese patrocinada pelo próprio Kivy: aquela que diz serem os sons musicais intrinsecamente expressivos, mesmo se privados de referências diretas à esfera emocional.

6 Refiro-me à edição histórico-crítica produzida por Dietmar Strauss: STRAUSS, Dietmar. Eduard Hanslick: Vom Musikalisch-Schönen. Ein Beitrag zur Revision der Ästhetik in [sic] der Tonkunst, vol. I: Historisch-keritsche Ausgabe, vol. II: Hanslicks Schrift in textkritischer Sicht, Mainz-London-New Yor-Paris-Tokio, Schott, 1990 (doravante citado VMS), que dá conta também de cada mínima variação, erros de impressão inclusive, graças a uma cômoda disposição tipográfica em colunas paralelas, e fornece preciosos documentos inéditos. E um infortúnio que um trabalho de tal importância não seja sempre impecável (produz uma certa impressão ver insistentemente estropiado na capa e no frontspício o subtítulo da obra; deve-se ainda registrar leves imprecisões no comentário e, na parte documental, uma reprodução anastática quase ilegivel da importante resenha de Robert Zimmermann, sobre a qual retornaremos). Um valioso estudo sistemático sobre as variantes foi conduzido por M. TODESCHINI LALLI, Vom Musikalische-Schönen di Eduard Hanslick dalla prima alla nona edizione, Firenze-Torino, Passigli-De Sono, 1993; com cada evidencia a pesquisa aponta, porém, para os anos imediatamente precedentes à publicação da edição crítica, da autora já mencionada. Para uma visão pontual dos estudos sobre Hanslick, no qual são tomadas em exame as várias edições de Vom Musikalisch-Schönen, inclusive aquelas pioneiras de PRINZ, F. Zur Würdigung des musikästheitschen Formalismus Eduard Hanslick, München, 1918, e SCHAEFKE, R. Eduard Hanslick und die Musikästhetik, Leipzig, 1992, cf. VMS, II, p. 20-65.

7 Dever-se-ia também levar em conta os erros de impressão jamais corrigidos, que contribuíram para tornar incompreensivel algumas passagens. O seguinte, por exemplo, foi acolhido como lição genuína também na tradução italiana: "Aquilo que uma bela melodia, em uma harmonia sábia, nos traz prazer e nos transporta não seriam a melodia e a harmonia em si, mas aquilo que significam: o sussurro da ternura, o ímpeto do ardor da batalha. [...] nós devemos, em primeiro lugar, separar inexoravelmente essas velhas metáforas: o sussuro? sim [sic], mas não da ternura ou da nostalgia; o ímpeto? certamente [sic], mas não do ardor da batalha. Com efeito, tanto uma quanto a outra estão em poder da música [..." (op. cit., p. 2 1). O sentido das palavras colocadas em itálico ("das Eine oder das Andere") é alterado por um erro de impressão - oder no lugar de ohne - introduzido, pois, na sexta edição ( $\mid 881$ ). Hanslick havia escrito, na verdade, das Eine ohne das Andere, e a tradução deve, portanto, ser modificada assim: "uma coisa sem a outra".

8 Cf. KIVY, 1993, p. 279.

9 VMS I, p. 10. 
Outro veio da pesquisa sobre Hanslick que deu nos últimos anos outras contribuições preciosas é aquele focalizado sobre a identificação das fontes do seu tratado ${ }^{10}$. Apesar dos adeptos do estruturalismo analítico considerarem II Bello musicale um trabalho pioneiro e revolucionário, podemos agora dar por certo que Hanslick não produziu teorias verdadeiramente originais, mas antes colocou em uma bela reprodução ideias de outros, recolhendo-as com letra desenvolta e substância, e quase nunca dando aos seus autores o devido reconhecimento" ". Dois desses casos podem ser recordados aqui a título de exemplo.

$\bigcirc$ primeiro diz respeito à tese hanslickiana - um dos pliares teóricos de seu volume - segundo a qual a forma musical deve ser entendida como "ritmo amplo"12. É exposta no terceiro capítulo; há alguns anos, Carl Dalhaus dedicou-lhe até mesmo um estudo específico. Agora, Geoffrey Payzant demonstrou que ela deriva literalmente de um artigo do esquecido crítico musical Bernhard Gutt (Potsdam, 1812 Praga, 1849), que com suas concepções já fortemente orientadas em direção ao formalismo contribuiu não pouco a mudar a opinião do jovem Hanslick, ainda ligado aos princípios da estética romântica ${ }^{13}$ :
HANSLICK:
○ elemento primordial da música é a eufonia, a sua essência, o ritmo. Ritmo [em sentido] amplo, enquanto concordância de uma constituição simétrica, e ritmo [em sentido] estrito, enquanto movimento alternado e regular

\footnotetext{
10 Cf. SCHMIDT, 1989, p. 91-120; G. PAYZANT, 1989, p. 133- 167.

II Cf. PAYZANT, op. cit., p. 124.

12 No original, "Ritmo in grande" (CIANI, 2000 [2017]). A expressão "in grande" é traduzida, em português, literalmente como "em grande" ou simplesmente "grande", a depender do contexto. Entretanto, no excerto de Hanslick, enquanto parte de um conceito, haveria mais sentido a tradução enquanto "amplo". O mesmo vale para a expressão "ritmo in piccolo" que aparece no mesmo excerto, logo a seguir, onde "in piccolo" significaria, literalmente, "em pequeno" ou "pequeno", mas que traduzi como "estrito", de modo a fazer mais sentido em português. Entretanto, para uma tradução mais precisa do conceito, seria necessário referir-se ao texto original em alemão sobre o qual se baseia a versão italiana utilizada como fonte pelo prof. Giani. Porém, visto que tal empreita foge ao escopo de minha intenção, que é aquela de somente traduzir o ensaio do prof., deixo tal tarefa de confrontamento aos interessados em levar adiante o desenvolvimento desse conceito ( $N$. T.).

13 Ivi, p. 132. O ensaio Dalhaus mencionado é Rhythmus im Grossen, "Melos/NZ", I, n. 3, 1975, p. 439-44 I. Naturalmente, não se mencionam palavras de Bernhard Gutt.
} 
de membros singulares no período métrico. (48). ${ }^{14}$

BERNHARD CUTT:

A essência da forma musical é o ritmo: ritmo [em sentido] amplo, isto é, euritmia de construção articulada de modo belo; ritmo [em sentido] estrito, [isto é] a flutuação regular dos membros singulares no período métrico. (Mose. Oratorium von Dr. Adolph Bernhard Marx, in "Bohemia", XIX, n. 45,10 de abril de 1846, s. p.).

segundo caso, ainda mais desconcertante, tem a ver, por sua vez, com uma passagem do primeiro capítulo, muitas vezes citado como prova do formalismo de Hanslick:

HANSLICK:

[na de 1858] O belo não há, em geral, nenhuma finalidade; ele é, de fato, pura forma, a qual pode certamente ser empregada com os fins mais diversos, segundo qualquer que seja o conteúdo do qual esteja preenchida, mas que, por si, não tem outra finalidade que si mesma. Se da sua contemplação surgem em quem observa sentimentos prazerosos, eles não dizem respeito em nada ao belo como tal. Eu posso antes apresentar um belo ao observador com a determinada intenção de que ele possa experimentar sobre ele prazer [na versão de 1874: sobre aquele experimentar], mas essa intenção não tem nada a ver [na versão de 1874: a ver] com a beleza da coisa produzida. $\bigcirc$ belo é e permanece belo mesmo se não suscita nenum sentimento, pelo contrário, mesmo se não é visto nem considerado; é, então, belo para o prazer de um sujeito contemplante, mas não por causa desse prazer ( $p$. 10).

Ora, esse texto não é de Hanslick: trate-se de um amplo fragmento da resenha de II Bello musicale publicada por Robert Zimmermann, docente praguense de filosofia e amigo do musicólogo, no "Oesterreichische Blaetter für Literatur und Kunst" em novembro de 1854 :

14 A partir de agora as citações de /l Bello musicale serão seguidas simplesmente dos números de página relativos à tradução italiana (ed. 1971) indicados entre parênteses; a tradução foi por vezes modificada para fazê-la mais fiel ao original, sem deixar isso claro todas as vezes. 
ROBERT ZIMMERMANN:

$\bigcirc$ belo não há, em geral, nenhuma finalidade; ele é, de fato, pura forma, a qual pode certamente ser empregada com os fins mais diversos, segundo qualquer que seja 0 conteúdo do qual esteja preenchida, mas que por si não tem outra finalidade, se se pode assim dizer, que não si mesma. Se da sua contemplação surgem em quem observa sentimentos prazerosos, eles não dizem respeito em nada ao belo como tal. Eu posso antes apresentar um belo ao observador com a determinada intenção de que possa experimentar sobre aquele prazer, mas essa intenção não tem nada o que fazer com a beleza da coisa produzida. O belo é e permanece belo mesmo se não suscita nenhum sentimento, pelo contrário, mesmo se não é visto nem considerado. De fato, o belo se funda sobre relações che permanecem sempre iguais a si mesmas (ZIMMERMANN apud VMS II, p. 130).

Hanslick interpolou o fragmento na segunda edição e o manteve em todas as sucessivas, retocando-o na quarta com duas variações sem qualquer importância. Temos aqui uma cadeia intertextual que parece feita propositadamente para confirmar a tese de Roland Barthes a respeito de se "escrever sob a ditadura do leitor" ${ }^{2}$. Em primeiro lugar, Zimmermann - seguidor da filosofia das relações de Herbart lê Hanslick em perspectiva coerentemente formalista. Depois, Hanslick lê Zimmermann que lê Hanslick: é um ex-romântico de formação idealista, está se afastando das convicções nutridas na juventude, encontrou na "apodrecida estética do sentimento"16 o perigoso inimigo a derrotar, e tende fortemente - mas não incondicionalmente - ao formalismo. A exposição do próprio pensamento produzida pelo amigo the aparece mais feliz do que malsucedida a ele mesmo (tanto que aquela resenha o induzirá também a retirar na revisão de 1858 várias referências à substância metafísica da música). O Hanslick revisor de Hanslick faz então seu o texto de Zimmermann leitor de Hanslick, e o copia novamente. Parece evidente que o plágio, para além dos aspectos desagradáveis que produz, pressupõe a adesão plena daquilo que é plagiado por parte daquele que plagia, e mesmo que, então, o escrito seja de Zimmermann, - conteúdo exprime um ponto de vista compartilhado por Hanslick. Todavia, as coisas não são de todo simples assim. Não se sentindo bem em aceitar até o fim a posição rigidamente herbartiana do amigo,

15 BARTHES, 1981, p. 139.

16 Esta expressão (verrattete Gefühlsästhetik) aparece somente no prefácio à primeira edição de Vom Musikalisch-Schönen. Cf. VMS I, p. 9. 
segundo o qual o belo consta somente de relações imutáveis, Hanslick altera a parte conclusiva da interpolação, e introduz, não sem alguma timidez, uma variante psicológica: depois de tudo, o belo existe para o prazer do sujeito contemplante. Agora, é exatemente o prazer estético, o Kunstgenuss, a colocar, segundo Hanslick, o ouvinte em relação com a substância do conteúdo espiritual (geistiger Gehalt) que informa a ópera musical. E o geistiger Gehalt, como veremos melhor mais adiante, não pode ser colhido se se perdem de vista os pressupostos idealistas que caracterizam a primeira edição, e que foram progressivamente ocultados nas sucessivas. Logo, assim como o Don Chisciotte de Pierre Menard 17, o texto de Zimmermann resscrito por Hanslick, ainda que idêntico ao original, não funciona da mesma maneira que no contexto ao qual pertence.

Dessas poucas referências, pode-se compreender quanta cautela é necessária ao lidar com o volume (e também, a propósito, que tantas simplificações e equívocos estejam muitas vezes na base da Rezeptiongeschichte de livros e obras de arte). $\bigcirc$ fato de que Hanslick tivesse confiado grande parte das próprias intuições a formulações aforísticas brilhantes e facilmente transportáveis explica como é possivel que II Bello musicale parecesse possuir a homogeneidade teórica que, na verdade, não tem, e assinalasse uma mudança de época na reflexão do século XIX sobre a música. Seguir o percurso das variações permite tocar com a mão a mistura de desenvoltura e de consistência especulativa que levam o autor a apropriar-se por todos os lados daquilo que lê para construir "a sua contribuição à revisão da estética muscal" 18 , e a agir em maneira obsessiva não tanto para obter uma maior coesão conceitual, mas, sobretudo, para trazer melhorias estilísticas, mesmo em passagens marginais.

Nas páginas que seguem, tratarei em primeiro lugar o conceito de forma à luz dos pressupostos idealistas do volume; procurarei depois ilustrar uma dificuldade central, que não foi até agora examinada pela literatura crítica sobre Hanslick, e que me induziu a falar de "dupla verdade": trata-se da dicotomia entre a linguagem técnica e a linguagem metafórica, que /I Bello musicale aborda, mas não explica profundamente, pondo uma séria interrogação sobre a própria possibilidade de se falar de modo sensato sobre música.

17 A referência, evidentemente, é a BORCES, 1971, p. 42-43.

18 É assim o subtítulo de $\bigcirc$ Belo musical, ausente na tradução italiana. 


\section{Ideia-forma-espírito}

A mais célebre tese da estética hanslickiana sustenta que os conteúdos da música são esclusivamente as suas formas ${ }^{19}$, e que é uma ilusão procurar-lhes a representação de conteúdos emotivos. Todavia, a noção de forma musical é para Hanslick possível somente se, em concordância, se considere a música enquanto uma linguagem sonora (Tonsprache); enquanto tal, ela articula uma substância conteudística. Mas, certas passagens de II Bello musicale parecem antes negar ao invés de promover a ideia de Tonsprache:

Da tentativa de conceber a música como uma espécie de linguagem são derivadas as opiniões mais danosas e confusas; todos os dias vemos as consequências práticas disso. Assim, sobretudo aos compositores dotados de fracas forças criativas, deveria parecer apropriado considerar como um falso princípio sensivel a beleza musical autônoma, para eles inalcançável, e exaltar, ao invés, a significação característica da música (79).

Hanslick aqui está empenhado em uma polêmica contra a intromissão de elementos operísticos, em particular do recitativo, na música instrumental. Nesse âmbito, o nexo música/linguagem vem por ele reduzido a mera retirada, da parte do compositor, de determinados modos construtivos típicos da música vocal, na esperança de tornar mais "eloquente" e expressiva a composição; mas, trata-se de uma descontextualização, que aos olhos de Hanslick pode provocar somente o caos. Nas páginas precedentes, ele afirma que tal confusão deriva do fato de que, enquanto a língua há um referente, e os sons dos quais é composta são apenas meios com a finalidade de exprimir algo que thes é completamente estranho, na música, que é privada de referentes, os sons têm um fim em si mesmos. Dentro dessa mecânica comparação entre música e linguagem verbal, vem contornado o problema de como a música pode se constituir como linguagem por si mesma. Todo caso, em vários outros pontos do volume a ideia é exprimida, mas não tratada organicamente. Hanslick se limita de novo a formulações aforísticas:

19 No original, a frase "(..) sostiene che [sic] contenuto [sic] della musica sono esclusivamente le sue forme, (...)" contém erros de concordância e a falta de um artigo definido masculino plural ("os", em italiano, "i") que foram corrigidos na tradução, e isso não alterou o sentido original (N. T.). 
A música não pode absolutamente "ascender à língua" rebaixar-se, precisar-se-ia dizer exatamente, do ponto de vista musical -, dado que evidentemente a música deveria ser uma linguagem potenciada (p. 71). Na música há sentido e finalidade, porém musicais; ela é uma língua que falamos e compreendemos, mas que não somos aptos a traduzir. Há um profundo significado, também em virtude de certas peças musicais, em se falar de "pensamentos", e, como na língua, também o julgamento especializado dintigue facilmente pensamentos verdadeiros de simples modos de dizer. Além disso, reconhecemos o sentido racionalmente realizado por um grupo de notas, chamando-o de uma "frase" (p51-52).

As expressões cautelosas e vagas ("deveria ser", "linguagem potenciada", "uma língua que não somos aptos a traduzir") entregam qualquer responsabilidade em se pensar a fundo esse nó central. $\bigcirc$ ponto está, porém, no fato de que a concepção da música enquanto Tonsprache, na qual a linguagem funciona como elemento de mediação entre a forma e a ideia, é ancorada nos pressupostos idealistas da primeira edição, que compeliram Hanslick a tocar um páthos dificilmente imaginável para quem conheça somente as reimpressões da décima. Basta relembrar as últimas linhas do texto de 1854, nas quais a música vem exaltada em modo todo romântico e metafísico, enquanto arte capaz de representar o universo:

A música age [sobre o ouvinte] não somente e absolutamente através de sua beleza específica, mas em igual tempo enquanto re-espelhamento [Abbild] sonoro dos grandes motos do cosmo. Mediante profundas e secretas relações naturais o significado dos sons se sinaliza por cima deles mesmo e nos faz sentir, na obra do talento humano, sempre e em igual tempo o infinito. Do momento em que os elementos da música - som, altura, ritmo, força, fraqueza se encontram no universo inteiro, o homem reencontra na música o universo inteiro ${ }^{20}$.

20 VMS I, p. 171 
Essa e outras passagens foram eliminadas, conforme já lembrado, logo após as críticas de Zimmermann. Embora a simpatia de Hanslick pelas teses do positivismo e a assunção de postulados do pensamento herbartiano se façam sempre mais evidentes de edição em edição ${ }^{21}$, a unidade original não pode ser removido do suporte teórico do volume sem comprometer a sua inteligibilidade. e ideia.

No início do segundo capítulo Hanslick trata do nexo entre forma

A cada uma [das artes] é próprio um círculo de ideias, que representa com os seus meios de expressão, como o som, palavras, cores, o mármore. A obra de arte singular encarna [verkoerpen] então uma determinada ideia como belo sensivel fenomênico. Essa determina ideia, a forma que a encarna e a unidade de ambas são condições do conceito de beleza, das quais não se pode prescindir o estudo científico de nenhuma arte (p. 20).

$\bigcirc$ que pretende com "ideia" Hanslick o diz um pouco adiante, em uma nota que reenvia à Estética de Friedrich Theodor Vischer, mas entrega uma clara ascendência hegeliana:

Vischer (Ästhetik $\$ 11$, nota) define as ideias determinadas enquanto reinos da vida, enquanto que a realidade delas é pensada correspondentemente a seus conceitos. De fato, "ideia" designa sempre o conceito puramente e perfeitamente presente na sua realidade (p. 25).

A última frase, na qual Hanslick traz a soma das observações de Vischer, é evidentemente uma paráfrase de notáveis formulações hegelianas: "Ideia é o conceito presente na sua realidade e posta em unidade com ela"22; "A ideia é [...] a unidade absoluta do conceito e da objetividade"23. Agora, todas as vezes que Hanslick sustenta que as formas são "cheias", e não vazias, pode articular esse pensamento somente em virtude da conexão idealista: a forma musical é por ele entendida enquanto energeia, enquanto autoprodução do espírito.

21 Sobre este ponto, cf. a monografia de TEDESCHINI LALLI, cit., cap. IV.

22 Cf. HECEL, 1986, p. 145.

23 Idem, p. 367 (grifos de Hegel). 
As formas que os sons produzem não são vazias, mas preenchidas, não são simples contornos de um vazio, mas espírito que se plasma a partir de si (p. 51 ).

- compor é um trabalho do espírito sobre um material capaz de acolher o espírito (p. 53).

No que concerne à composição [...], é preciso manter presente que é um contínuo configurar [Bilden], um formar [Formen] mediante relações sonoras (p. 75).

Embora clara e progressivamente removida no percurso das variações, a conexão entre forma e espírito é decisiva, e isso explica como é possivel a passagem tomada de Zimmermann, que trouxemos por inteira mais acima, exprima e ao mesmo tempo esconda o quanto Hanslick tem em mente: as "relações" (Verhaeltnisse), postas na base da obra de arte por Zimmermann, em linha com a filosofia das relações de Herbart, são de um todo estranhas, seja devido ao fator da processualidade quanto àquele do espírito criador. Então, a expressão chave "o belo é pura forma" não significa a mesma coisa nos dois contextos. Zimmermann pode, de fato, denunciar o uso impróprio da linguagem de grande parte da crítica musical, sustentando que definir "lírica”, "dramática”, etc., uma arte que consiste somente de relações sonoras é um absurdo ${ }^{24}$. Hanslick é muito menos radical: para ele o discurso sobre a música tem sentido enquanto um discurso sobre as formas "preenchidas". Nele vem a realização do espírito enquanto espírito formador; e se as formas sonoras são as "encarnações" das ideias fora da linguagem sonora, pode ser constituída uma metalinguagem. Mas, como se articula tal metalinguagem? $\bigcirc$ que significa, em sentido elevado (em sentido estético), falar ao redor da ${ }^{25}$ música?

24 ZIMMERMANN, apud VMS II, p. 132.

25 No original, o prof. Giani usa a palavra italiana "intorno", que literalmente quer dizer "em torno a". Em português, não há muito sentido essa expressão na frase em que é empregada ("falar em torno à música". Em italiano, "parlare intorno alla musica"). Porém, considerando que, no trecho, o prof. se refere anteriormente à metalinguagem, há sentido usar "ao redor de", como de fato fiz, uma vez que a metalinguagem não aborda uma linguagem em si, mas como se fala de uma linguagem (N. T.). 


\section{Gradação metafórica}

Como visto, Hanslick parece por vezes tentado a afirmar, sobre o caminho dos românticos, que a música, enquanto reino do inefável, não pode ser objeto de praticas discursivas: "o seu reino efetivamente "não é deste mundo"' (p. 5 l). Todavia, "nós falamos e compreendemos" esta língua sui generis, e a compreensão se funda sobre o fato de que nela "há sentido e uma sequência lógica". Trata-se de demonstrá-los.

Em II Bello musicale, a explicação do sentido na música se estrutura em níveis diversos ${ }^{26}$. $\bigcirc$ primeiro é oferecido pela linguagem especializada: pela terminologia da teoria musical. Encontramo-lo na obra no segundo capítulo, na bem conhecida análise do tema principal da abertura Prometeo de Beethoven (p. 27-28). Trata-se, na realidade, de uma descrição (a) das simetrias que governam o desenvolvimento por grupos de compassos, segundo o esquema $([1+1]+2)+([1+1]+2)$, (b) do processo harmônico (em suma, um movimento cadencial do primeiro ao quinto grau, este último articulado sobre as sucessivas direções do acorde de sétima de dominante), por fim (c), da conexão entre processo harmônico e estrutura rítmica. Essa descrição vem apresentada como exposição do conteúdo do tema: "É absolutamente impossivel reconhecer neste tema outro conteúdo além daquele referido" (p. 28). É o caso de ater-se um pouco sobre essa afirmação e sobre aquilo que a precede. De fato, Hanslick demonstra aqui um tipo de estrabismo analítico, bloqueando de fato o caminho para um desenvolvimento mais fecundo de suas próprias concepções. Em termos semióticos, poderemos dizer que ele está tentando produzir uma análise componencial em forma de dicionário, enquanto recusa (ou omite) a informação enciclopédica. A dificuldade principal está, acima de tudo, no papel atribuído ao exemplo: a metalinguagem relativa ao tema do Prometeo vem produzida isolando o tema da composição da qual faz parte. Mas, também, em música, existem propriedades de um "texto" que não podem ser propriedades da "frase"27. As "ideias" que fazem de cada cada obra

26 Seguindo a terminologia de II Bello musicale, eu também falarei de sentido para indicar a totalidade do campo da significação musical: mas é oportuno precisar que se trata de um campo que, seguindo os numeroso estudos de Hans Heinrich Eggebrecht, poderia ser articulado nos dois níveis do sentido verdadeiro e próprio, relativo à significação das estruturas musicais enquanto tais, colhidas em seu funcionamento no interno da lógica da composição, e do conteúdo, que Eggebrecht exprime com o mesmo termo Cehalt usado por Hanslick, e que se refere à "substância semântica" da música. Cf. ECCEBRECHT, 1987; idem, 1996, p. 543-556.

27 Cf., por exemplo, ECO, 1995, p. 14- 15. 
musical na sua inteireza aquilo que é - isto é, trabalho do espírito sobre o material capaz de acolher o espírito - não podem ser articuladas sobre a base da gramática rítmico-harmônica que caracteriza os temas principais. Essa dificuldade foi obtida logo após o lançamento do volume do diretor da "Neue Zeitschrift für Musik" Franz Brendel, embora também em uma perspectiva notadamente hegeliana:

Deve-se, por fim, observar [...] que a tentativa de apanhar verbalmente [o conteúdo da música] é tanto mais difícil quanto menos desenvolvido é o pensamento musical que se tem diante. Se se quer realizar uma tentativa similar, seria naturalmente melhor ater-se à inteira composição, ao núcleo desenvolvido, ao invés do tema, que the constitui o núcleo não ainda desenvolvido 28 .

A Hanslick, em resumo, escapa o próprio plano sintático da forma entendida enquanto "ritmo amplo", que sozinho pode permitir o atrelamento à dimensão semântica; o que o conduz a formulações contraditórias e ambíguas no último capítolo, aquando põe a intorrogação sobre o que seja forma e coisa seja ${ }^{29}$ conteúdo em música. A passagem crucial está na questão se um mesmo tema, repetido em um registro diferente ou tocado por outro instrumento, modifica forma ou conteúdo. Hanslick parece afirmar sobretudo que o tema subsiste enquanto forma, e se limita a mudar de cor, assim como acontece ao se olhar uma mesma paisagem através dos vidros coloridos de um alpendre.

Tal infinita mudança de cor das mesmas formas, do mais áspero contraste a mais fina nuance, é absolutamente característico da música e constitui um dos lados mais ricos e mais perfeitos da sua eficácia (p. 130; grifos meus).

A metáfora da mudança de cor ignora o problema acerca da existência ou não do conteúdo. Todo caso, no parágrafo seguinte a perspectiva vem invertida: agora Hanslick nos diz que uma instrumentação diversa modifica a forma do tema:

28 BRENDEL, 1855 , p. 90.

29 No original em italiano, falta o verbo "essere" (ser) em sua forma condicional ("sia"), a fim de que a frase tivesse sentido, e, portanto, completei-a (N. T.). 
Uma melodia elaborada para piano, que seja depois instrumentada por outra pessoa, recebe, sim, uma forma nova, mas não somente uma forma, ela é já um pensamento formado (p. 130; grifos de Hanslick).

No curso de poucas linhas, então, Hanslick parece tomar de volta com uma mão aquilo que havia acabado de dar com a outra. A contradição reside, porém, no próprio conceito de forma: na perspectiva de Hanslick, as duas afirmações, mesmo que isso soe paradoxal, são plausíveis. No famoso aforisma que consagra ser conteúdo da música toenen bewegte Formen, "formas sonoramente movidas" (p. 49)30, de fato, Hanslick fala de "formas" no plural: a composição é uma sequência de formas, a "estória" das ideias que ela encarna se desenvolve toda numa sequência, e nos arranjos ricos de sentido que assume no plano da sintaxe global e não simplesmente local. É então verdade que o tema digamos: a "frase" com as suas propriedades - conserva a mesma forma quando surge aos poucos instrumentado em maneiras diversas e em tonalidades diversas; mas em outro plano de articulação - digamos: o plano das propriedades do "texto" - ele assume sempre novas formas.

Agora importa observar que Hanslick não é de todo fiel à posição analítica que impôs a si. Em vários outros pontos de II Bello musicale, de fato, sua linguagem tenta aventuras hermenêuticas muito diversas, isto é, abandonando o plano da gramática e da sintaxe local para aceder àquele da semântica. Eis o que afirma Hanslick sobre Beethoven:

\begin{abstract}
A pesquisa estética [...] escutará e acreditará somente naquilo que a própria obra exprime. Por isso, nas sinfonias de Beethoven [...] encontrará um ímpeto tumultuado, uma luta, um delírio não correspondido, um desafio de quem é consciente da própria força [... ] (p. 65-65).
\end{abstract}

É evidente que se o único tipo de esposição esteticamente válida do conteúdo da música fosse aquele produzido no caso do Prometeo, Hanslick não poderia nunca falar desta maneira: contudo, a passagem citada há pouco não é nada menos que a representação verbal de um geistiger Gehalt. De forma concisa, essas afirmações nos dizem

30 Proponho uma versão literal do texto; a tradução italiana tem "formas sonoras em movimento" (p. 49). 
algo sobre algumas ideias cujas formas musicais "preenchidas" seriam "encarnações", nas quais se realizariam o espírito formador. Hanslick se precaveu ao indicar os limites da linguagem:

Dado que a música não há modelos na natureza e não exprime conteúdo conceitual, pode-se falar dela somente com áridos termos técnicos, ou ainda, com imagens poéticas [... ]. Aquilo que para qualquer outra arte não é descrição, para a música é já metáfora (p.51).

Mas a precipitação não modifica em nem uma vírgula a dificuldade: na passagem sobre Beethoven, Hanslick afirma de modo claro que os conteúdos são "encontrados" através da "pesquisa estética", não são fruto das fantasias literárias de um filósofo diletante. E tendo sustentado desde o início de seu tratado a necessidade de introduzir na estética o método científico ${ }^{31}$, de duas, uma: ou Hanslick se contradiz terrivelmente (e sucede que o discurso crítico está encerrado), ou ele considera plausível e objetiva a explicação dada acima. Isso é tão verdadeiro que, no curso do volume, encontramos mobilizada uma bateria de atributos qualificados como "ideias" (cf. Tabela 1).

Parece, então, que o texto, se não queremos liquidá-lo enquanto obra incoerente de um pensador ruim, funciona de um modo mais complexo em relação à dicotomia tecnicismos/imagens poéticas. Para começar, elementos metafóricos se insinuam já no cerne de sua análise técnica. Eis como vêm por ele "coloridas" as observações sobre o tema do Prometeo beethoviniano:

As notas do primeiro compasso, depois de abaixadas à quarta inferior, sobem novamente serpenteando, rápidas e leves; o segundo compasso repete exatamente o primeiro; o terceiro e quarto continuam o mesmo procedimento em um âmbito mais vasto: gotas de esguicho espirradas para cima, que recaem para reproduzir, nos quatro compassos seguintes, a mesma figura e o mesmo complexo de figuras (p. 27).

31 "A investigação do belo, se não quer tornar-se nem um pouco ilusória, deverá aproximar-se ao método das ciências naturais ao menos o quanto necessário para tentar colher as coisas em sua semente e pesquisar que coisa nela há de duradouro, de objetivo, uma vez que prescinda das mil e diversas impressões mutáveis" (p. 7). 
Por outro lado, não seria dificil contestar a mesma oposição entre metáfora e tecnicismo. Somente através de metáforas pode-se afirmar que as notas "sobem" e "descem". A terminologia musical, substancialmente, é composta de uma série organizada daquilo que a retórica chama de catacrese, isto é, metaforas já não mais entendidas enquanto tal: subir, descer, dominante, tônica, cadência de engano, etc. Todavia, seria míope negar que, entre a metáfora do sair e descer e aquela do esguicho, subsiste uma diferença de planos. $\bigcirc$ ponto agora é: colocada a diferença básica entre metáforas "mortas" (os tecnicismos) e "vivas" (as imagens poéticas), como se pode distinguir, dentro dessas últimas, a separação das imagens poéticas das imagens que veiculam o sentido musical? Por que, segundo Hanslick, é errado dizer que uma dada música exprimiria este ou aquele sentimento, $e$, ao invés, é legítimo dizer que em outra música uma pesquisa encontra "luta"?

Tabela 1: Predicados da música, segundo /l Bello musicale

\section{Verbos}

pressar

crescer

diminuir

enfurecer

ondular

retardar

sussurrar
Adjetivos

banal

sombrio

doce

elegante

enérgico

orgulhoso

fresco

gélido

gracioso

intimo

leve

nebuloso

vaporoso

vivaz
Expressões e locuções verbais*

harmonioso em geral

desejo não correspondido

impeto tumultuado

simplicidade no proceder

desafio de quem é consciente

da própria força

32 No original, está escrito em latim (coniunctiones verborum), porém, preferi, por uma questão de compreensão, traduzir para o português (N. T.). 
A resposta está no fato de que a metalinguagem analítica que caracteriza II Bello musicale se move por dentro de uma estrutura em três níveis. Para torná-la mais evidente, e por comodidade expositiva, premitam-me introduzir aqui a noção de gradação metafórica, modelada sobre o fenômeno da assonância vocálica. No "grau zero" da metáfora encontramos o estrato que Hanslick chama de os "áridos tecnicismos": as metáforas cujo desvio de imagem é ocultado pelo desgaste produzido pelo uso. É com ele que vem construida a análise do Beethoven. "grau forte" corresponde, ao invés, ao estrato da metáfora cheia e desenvolvida; no exemplo citado, à imagem do esguicho. Há, porém, um grau intermediário, absolutamente necessário à articulação do discurso inteiro: chamá-lo-emos de "grau reduzido". Um primeiro exemplo de grau reduzido está no adjetivo inocente que Hanslick usa para descrever o movimento das notas rápidas tocadas pelos violinos em piano e staccato: elas são definidas enquanto leves. Se tivessem um andamento menos movido, e tivessem sido confiadas por Beethoven aos metais em fortissimo pontuadas pelos tímpanos, Hanslick não teria tido qualquer dificuldade em defini-las como "pesadas", e a imagem do esguicho não the teria sequer passado pela cabeça. Em discursos sobre música, metáforas do gênero são quasi-tecnicismos, visto que, em relação àqueles, apresentam apresentam pequenos desvios de imagem; mas à diferença do grau zero, no grau reduzido conflui a reserva lexical que consente em iniciar a derivação de interpretação em cujo auge se encontra a metáfora empregada. Agora, Hanslick não pretende exatamente liquidar essa reserva lexical como mera sugestão poética:

Dado que entre o movimento no espaço e aquele no tempo, entre as cores, a sutileza, a grandeza de um objeto e a altura, o timbre, a intensidade de um som, existe uma analogia bem fundada, podemos efetivamente pintar musicalmente um objeto; mas querer representar com os sons o sentimento que suscita em nós a neve que cai, o galo que canta, o lampejo do raio, é simplesmente ridículo (p.37) $)^{33}$.

Embora Hanslick tenda a banalizar essa conexão, limitando-a

33 Hanslick parafraseia aqui, sem citá-lo, o ensaio de Johann J. Engel Ueber die Malevey in der Tonkunst (1780) e as observações críticas desenvolvidas sobre ele por Hans G. Naegeli em suas Vorlesungen über die Musik mit Berücksichtigung der Dilettanten (1826). 
aos casos de música imitativa, ela é de máxima importância na sua concepção, e que se desliga de uma característica basilar da interpretação ocidental da música, que diz respeito tanto à esfera poética que àquela estética: a espacialização. A analogia é bem fundada porque a espacialização aparece como uma absoluta obviedade; basta pensar na ideia de escala musical ${ }^{34}$. Parece óbvio definir como "alto" um som agudo, "baixo" um som grave, "leve" um conjunto de sons em sucessão e separados, rápidos e em baixa intensidade, e assim por diante. A possibilidade de ler, em música, um sentido que não seja caráter meramente gramatical e sintático, mas que germine das estruturas sintáticas, é ancorada a essa aparente obviedade. É extremamente fácil passar da conexão analógica de tipo espacial a formas de significação mais complexas.

Podemos ilustrar tudo isso com um exemplo. No IV ato do Otello de Verdi, a entrada silenciosa de Otello no quarto de Desdemona, que tinha acabado de se adormentar depois de ter recitado a Ave Maria, é acompanhado pela orquestra de uma passagem memorável: um salto descendente do Lá bemol-5 dos primeiros violinos ao Mi- I dos contrabaixos (cf. Exemplo Musical 1). Um efeito tão potente que Richard Strauss sentiu a necessidade de inseri-lo em sua edição do Tratado de Instrumentação de Berlioz ${ }^{35}$.

34 Procurei explicar a gênese dessa metáfora espacial em relação à história da notação musical em meu estudo "escala música" Casos de uma metafora, in Le parole della musica. Studi di lessicologia musicale, sob a resp. De F. Nicolodi e P. Trovato, III, Firenze: Olschki, 2000, p. $31-48$.

35 Cf. BUDEN, 1988, p. 411. 
(Adagio. . $=63$ )
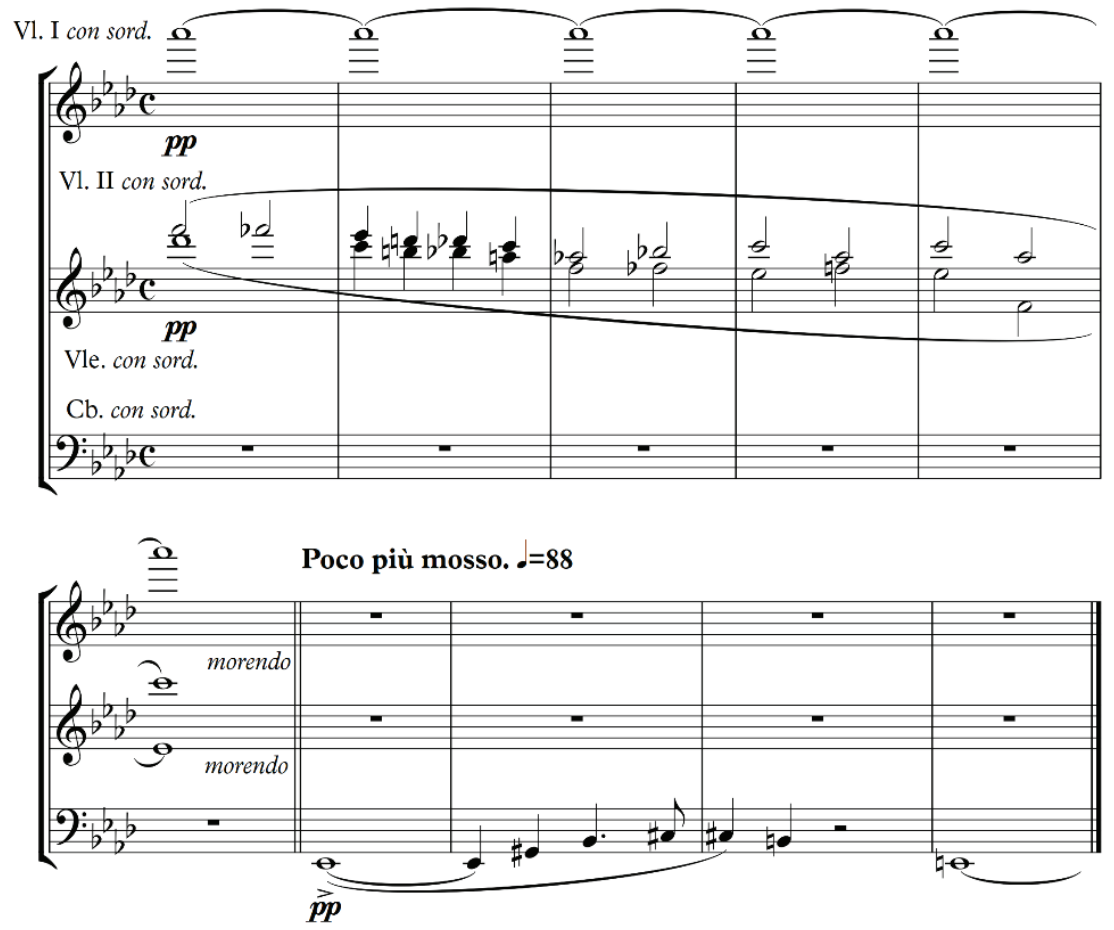

Exemplo Musical I: G. Verdi, Otello, Ato IV ${ }^{36}$

Do ponto de vista estritamente formal, essa passagem contém, como é óbvio, somente propriedades que podem ser descritas em termos harmônicos (o Mi, vindo depois do acorde de quarta e sexta de Lá bemol sustentado pelos violinos e violas - último compasso antes do Poco piu mosso - soa como um VI grau abaixado) e tímbricos (todo o episódio é executado em pianissimo das cordas com sordina). Isso é rico, porém, de um sentido que vai além da esfera dos dados técnicos: para dizê-lo com as palavras de Hanslick, "encarna uma ideia" que pode ser descrita a partir da análise. Desdemona é conotada musicalmente pelo Lá bemol maior e pelo registro particular dos arcos. A estratégia composicional que privilegia o registro agudo em pianissimo, a tonalidade maior e

36 exemplo musical aqui exibido foi feito pelo próprio prof. Giani, a partir da grade orquestral. 
- tempo Adagio criam uma analogia com a ideia de quietude e a esfera religiosa: o registro superagudo é associado, em virtude da espacialização, ao céu, logo, aos pensamentos elevados e espirituais, etc., e o movimento lento e diatônico em pianissimo, à tranquilidade. Nesse quadro sonoro estabelecido, o Mi dos contrabaixos entra como uma entidade estranha seja no plano harmônico que no registro, e funciona como um símbolo perfeito da situação dramática. A distância harmônica do Mi da tonalidade de Lá bemol representa uma distância na esfera emocional: aquela que divide Otello - já convencido da traição de Desdemona e determinado a cometer o delito - de sua esposa. Passando ao campo das classes de alturas, encontramos uma fortíssima carga simbólica também na enorme disparidade de registro (quase cinco oitavas), que permite associações de sinal oposto ao Lá bemol dos violinos e violas: grave=baixo=escuro, escuridão mental, ameaça, etc. (A passagem exprime com meios puramente musicais uma metáfora do uso comum: isto é, Otello "se afundou"...). Agora, se definimos grave o Mi dos contrabaixos não fazemos nada além de descrevê-lo; se o definimos como ameaçador o estimo, por outro lado, interpretando, e isso poderia suscitar os protestos de um formalista rigoroso (por exemplo, Zimmermann). Mas a interpretação se enquadra na ideia, que não é de certo exclusiva de Verdi nem de seus exegetas mais fantasiosos, que "grave", enquanto termo técnico, pertence ao grau zero do paradigma metafórico, e equivale a "baixo", que, por sua vez, pertence ao grau reduzido, e que esse último funciona, a seu tempo, como metáfora de qualidade moral: com as quais entramos com tudo na esfera das associações de grau forte. Nesse sentido, e somente nesse, o efeito tem uma causa que reside na estrutura compositiva, a qual por si própria não sabe obviamente nada de apagamento psíquico e de agressividade criminal.

É então em virtude desta passagem do grau zero ao grau reduzido, e da transmutação do grau reduzido ao grau forte do paradigma metafórico, que Hanslick pode falar de Beethoven do modo em que vimos. Nenhuma análise simplesmente gramatical da Quinta Sinfonia, conduzida com os "áridos tecnicismos", poderia encabeçar a ideia de "luta". Mas, aglomerados de acordes de tensão em fortissimo, pausas ao improviso que engrossam a continuidade sintática, dualismo temático, construção teleológica (o baricentro arquitetônico do primeiro 
movimento é transferido para a coda ${ }^{37}$ e toda a sinfonia gravita em direção à transição final), emprego de uma instrumentação inusitada no quarto movimento, para acentuar a força resolutiva ao aporto na tônica de Do maior, etc., tudo isso faz parte das suas propriedades sintáticas, que no plano da metáfora desenvolvida - ou melhor: no plano da metaforização de elementos compositivos no qual pode ser recolhido uma forte valência simbólica - podem ser abreviadas no topos da luta e da superação uma modalidade de leitura solidamente estabilecida no curso da história da recepção ${ }^{38}$. $\bigcirc$ paradoxo da música está, assim, no fato de que ela, de um lado, consta de sinais que têm por conteúdo somente si mesmos, e de outro, desenvolveu/instou no curso da história concatenações dotadas de sentido que compõem, de tempos em tempos, um quadro plausivel e coerente. Hanslick não renega de todo essa dimensão semântica; não pode prescindi-la tampouco quando a dimensiona drasticamente. A sua célebre refutação da capacidade da música em representar sentimentos, exposta em seu capítulo II, não significa nenhuma exclusão de ideias e conteúdos. Não os sentimentos, mas a dinâmica deles é expressada pela música:

A música pode imitar o movimento de um processo psíquico segundo as suas diversas fases: presto, adagio, forte, piano, crescendo, diminuendo. Mas, o movimento não é nada mais que uma particularidade, um momento do sentimento, não próprio sentimento (p. 24).

Todavia, o movimento e a dinâmica são também "o momento [das ideias] que a música sabe definitivamente conduzir” (p.25). E essa associação permite a Hanslick elevar sempre e mais alta a linguagem explicativa, até o ponto de falar sobre música em uma perspectiva ideal geral:

Por exemplo, aquele dado adagio doce e harmonioso apresenta como beleza sensivel a ideia do doce do

37 Grifo meu, a fim de fazer notar tratar-se de um conceito musical que, normalmente, não é traduzido, e que indica a seção final de uma obra musical, embora em italiano haja também o significado comum, que é "cauda/rabo". Assim será feito com demais expressões musicais comumente usadas em italiano (N. T.).

38 Para todo o argumento, C. H. H. ECGEBRECHT, Zur Gesichchte der Beethoven-Rezeption, nuova ed., Laaber, Laaber Verlag, 1996. 
harmonioso em geral. A fantasia da maioria, que de bom grado põe a ideia da arte em relação à própria vida psicológica, conceberá esse fenômeno sonoro como algo ainda mais alto, por exemplo, como a expressão da amena resignação de uma alma reconciliada com si mesma, e subir, assim, até o pressentimento do absoluto (p.23-24; grifos meus).

Para desenvolver essas e outra reflexões, Hanslick não pode absolutamente render-se aos tecnicismos, mas deve pressupor a conexão analógica, e julgá-la algo que é radicado na própria linguagem musical. Não obstante o seu despeito em relação aos predecessores, desse ponto de vista não faz nada mais que prolongar a tese. Já Descartes, em seu juvenil Compendium musices (1618), tinha estabelecido uma conexão analógica entre ritmos e emoções:

No que concerne [...] as diversa emoções que a música pode suscitar com a variedade dos seus ritmos, digo em geral que aqueles mais lentos suscitam em nós estados de alma mais tórridos, como a languidez, a tristeza, o medo, a soberba, etc., aqueles mais velozes suscitam estados de espírito mais tumultuosos, como a alegria, ecc ${ }^{39}$.

Um século e meio mais tarde, Johann Jacob Engel, movendo-se no mesmo campo de Descartes, havia invertido a posição, sugerindo que uma representação de elementos extramusicais de caráter não acústico pode ter lugar mediante a tranzendentale Aehnlichkeiten, "analogia transcendental"40. E o reconhecimento não para no passado. Em nossos dias, a pequisa sobre a significação musical acolhe ainda essa abordagem, atualizando-a e com qualquer variação terminológica. No lugar das analogias transcendentais encontramos, por exemplo, as

39 Descartes, Breviario di musica, ZANONCELLI L. (org.), Firenze: Pasigli, p. 76, 1990.

40 Cf. J. J. ENCEL, Uber die Maerey in der Tonkunst, Berlim: Voss, 1780, p. 9. As analogias são definidas transcendentais, porque põem em relação fenômenos percebidos com sentidos diversos: por exemplo, lentidäo e velocidade se encontram tanto em uma série de sons quanto em uma série de impressões visivas. Hanslick, como visto, manteve presente de perto esta passagem (cf. acima a nota 26). 
associações sinestésicas propostas por Leonard Meyer ${ }^{41}$.

Entre a descrição técnica de um lado e a "ideia do doce e do harmonioso em geral", ou do "desejo não correspondido" do outro, advém,

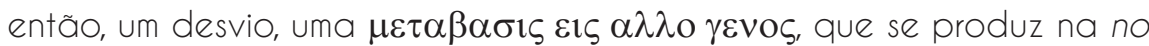
man's land da linguagem metafórica que chamei de "grande reduzido". E quando Hanslick rebate, a propósito de tais atributos, que "não se pode fazer menos que isso" (p.55), está indiretamente dizendo várias coisas: que a música tem uma semântica, que tal semântica não faz sentido enquanto metalinguagem analítica ou exegética estiver munida de termos técnicos caros ao "formalismo", e que seria a bancarrota da estética musical se as perífrases em torno das ideias encarnadas na estrutura compositiva devessem ser tiradas de circulação. Apesar das aparências, o pai do formalismo moderno pode ser definido com iguais direitos um conteudista relutante, para quem a significação musical permanece, em última análise, um mistério: "Na música nós vemos conteúdo e forma, matéria e configuração, imagem e ideia, fundidas em obscura e indissociável unidade" (p. 129; grifos meus).

\section{Sobre a atribuição por direito de propriedades semânticas à música}

Existe, assim, uma dupla verdade em Hanslick. A primeira privilegia o grau zero da linguagem analítica, e emerge na descrição do tema beethoviniano, que vem apresentada, lembrando, enquanto exposição do conteúdo do tema. Ela tende a banir do discurso estético sobre a música as imagens poéticas, a fazer coincidir o plano conteudístico da música com o plano gramático-sintático (aquele que Hans Heinriche Eggebrecht chama de plano do sentido) e a conferir ao estrato da terminologia técnica - ao grau zero - um valor fundativo para a reflexão. Essa verdade encarna o momento "formalista" da estética de Hanslick, e, separada do contexto que a abriga, teve uma sorte quase incalculável durante o século XX. A segunda verdade é ligada, ao invés, à "analogia bem fundada" entre os sons e as conexões na realidade; articula-se no

4 I Cf. M. GARDA, Topoi retorici ed ermeneutica musicale: un problema di metodo, in G. STEFANI, E. TARASTI, L. MARCONI (ed.), Musical Signification, Between Rhetoric and Pragmatics, Proceedings of the $5^{\text {th }}$ International Congress on Musical Signification, Bologna, CLUEB, 1998, p. 159-169: 160-161. 
grau forte, mas tem suas raízes no estrato linguístico do grau reduzido. Ela exprime o momento "conteudístico" da estética hanslickiana, que não somente não tem nada de revolucionária, mas se encontra mesmo inserida em uma longa tradição. À constituição das relações analógicas entre música e mundo externo se deve a construção da Affektenlehre e da retórica musical, a sua inversão, na concepção romântica da música enquanto linguagem poética de ordem superior, mesmo até nas várias formas de música programática. No que diz respeito a esse ponto, vimos como o texto de Hanslick oscilava desde o início entre um formalismo "puro", direcionado em sentido positivista e tecnológico, e a perspectiva de uma semanticidade moderada, que aprofunda e promove uma virada purgada dos aspectos mais degradados do sentimentalismo romântico tardio. Deve-se à história singular das reformulações do volume, assim como à parábola da recepção - condizionada pelo fato que enquanto crítico musical muito influente Hanslick se torna pouco a pouco o precursor do "partido da conservação" e o inimigo número um da "música do devir" de Wagner e Liszt - se a ênfase sobre a forma presente de II Bello musicale terminou por absconder a segunda verdade e o momento da significação ideal em música.

Parafraseando uma expressão de Gyoergy Lukács, proporia introduzir uma definição adicional dessa capacidade de significação, tratando de aprofundá-la logo mais: semântica atribuída por direito ${ }^{42}$. Parece-me que a noção de atribuição de direito exprime bem os dois fatores contraditórios emersos na análise de Hanslick, e em igual tempo a modalidade da ligação deles. De um lado, enquanto conjunto de "puras" relações sonoras, a música não é capaz de articular com os próprios meios fenomênicos um conteúdo determinado; ela sofre de anartria, e resta à linguagem verbal, sob a forma de explicação hermenêutica, atribuir-lhe o conteúdo. Por outro lado, porém, tal atribuição tem o direito de existir, não é um mero arbítrio fruto de fantasias poetizantes, porque dá voz a complexas associações analógicas, estrutura-se no curso da história, que ligam a música à realidade conceitual e emocional através do próprio estrato de seu sentido compositivo, e muito frequentemente são previstas conscientemente pelo compositor. É preciso sublinhar que esse processo de atribuição advém por inteiro na esfera da razão logocêntrica; e pode-se também fazer uma hipótese de que, com a quebra dos pressupostos do logocentrismo, todas as concepções semânticas colapsaram, e foram substituídas por outras

42 A "atribuição de direito" (Zurechnung) é desenvolvida por Lukács em conexão com sua teoria da consciência de classe: cf. LUKÁCS E PIANA, 1967, p. 94. 
formas de atribuição (quem afirma que a música "não significa nada" realiza também um ato de atribuição, mesmo que de sinal negativo).

Assim como se fala de época do baixo contínuo ou do processo temático, do mesmo mode poder-se-ia dizer então da "época da semântica musical atribuída por direito". Esta se inicia mais ou menos com o advento do madrigal, no primeiro terço do século XV, e entra definitivamente em crise nas experiências da vanguarda pós-bélica. Hanslick errou ao considerar naturais as "profundas e secretas relações" mediante as quais "o significado dos sons elevam-se acima deles mesmos", e nos fazem "sentir em igualdade ao infinito", como escreveu ao fim da primeira edição de II Bello musicale, ou, sob um ponto de vista mais restrito, a pregnância simbólica da passagem do Otello analizado acima. A linguagem de Verdi é um exemplo do uso analógico das estruturas musicais no final do século XIX - um século que assistiu ao máximo florescer dessa concepção - e se formou em relação ao sistema determinado do material musical; a natureza com a qual tem a ver a semântica atribuída è, em todo caso, uma segunda natureza. Que tais concatenações imersas na história tendam a envelhecer e a tornar-se, no fim, compreensiveis ou estranhas, não muda em nada, porém, o fato de que uma vez pudessem subsistir em plena legitimidade, e que tal legitimidade pudesse ser reconstruida por via historiográfica aquando colapsaram as condições que a tornavam atuais, ou vir substituida por novas concatenações. $\bigcirc$ ataque da Sinfonia Haffner de Mozart, com seu tema formado por intervalos amplos expostos por toda a orquestra em fortissimo e uníssono, no final do século XVIII, condizia perfeitamente com os cânones do sublime. Hoje, depois de Beethoven, Brahms, Wagner, Schoenberg, Stravinski, ela nos parece, na melhors das hipóteses, graciosa e elegante ${ }^{43}$. A metáfora musical, nesse caso, tornouse uma catacrese musical.

A atribuição de propriedades semânticas por direito à música, como correlata a uma percepção (do compositor, e não menos do ouvinte) produtora de associações, legitima o emprego, no discurso musical, da metáfora, que pode parecer um absurdo somente se aceita

43 Cf. M. GARDA, Musica sublime. Metamorfosi di un'idea nel Settecento musicale, MilanoLucca: Ricordi-LIM, 1995. Poder-se-ia ajuntar que a mais recente recepção de Beethoven, com a sua insistência sobre a prática executiva "filologica" e com o abandono da linha interpretativa idealista e pós-wagneriana de regentes como Klemprer, Furtwaenger, Jochum, parece de fato querer redimensionar o topos da luta. As simpatias maiores vão hoje em direção a um Beethoven reconduzido ao século XVIII, mais iluminista tardio que pré-romântico, e volumetricamente mais magro e elegante que titânico e grandioso. 
como válida unicamente sob uma perspectiva científica exasperada; como se o único conceito regulativo aceito como óbvio fosse aquele do rigor tecnológico. Hanslick, enquanto problemático alferes do formalismo, teve sem dúvida uma parte de responsabilidade na formação desse novo conceito regulador, que caracteriza grande parte do século XX. Mas mesmo hoje, que o mito da ciência analítica começa a ser considerado com qualquer distanciamento, é possivel, de uma parte, sublinhar sem animosidade os aspectos do pensamento de Hanslick que vão na mesma direção de seus adversários, de outra, reconsiderar de modo mais tranquilo o trabalho hermenêutico que tenta trazer para a linguagem a música. Refletindo sobre ela, ou nos servimos de metáforas - talvez controladas e "limpas" - ou, obedecendo à máxima de Wittgenstein, devemos nos calar; como qualquer tecnocrata da análise fez de verdade ${ }^{44}$. A aventura da interpretação verbal dos objetos sonoros é interminável, mesmo se não for possível por quer como substituto da música, quer como atemporal o "lugar da aproximação da música à verdade de si mesma"; ela constitui não menos que um enriquecimento incalculável do nosso campo de experiência, porque representa o modo com o qual nos apropriamos do nosso passado e o fazemos sempre de novo um fragmento do nosso presente.

44 Penso em Hans Keller, cujo culto pela cientificidade da análise o levou muito rápido a um verdadeiro e particular ódio pelas simples descrições e pela linguagem metafórica ("The descriptive is senseless, the metaphorical usually nonsense"), e a desenvolver uma forma de wordless analysis que consiste exclusivamente em exemplos musicais oportunamente dispostos, sem qualquer comentário (a citação foi retirada de KELLER, 1956, p. 48-49). 


\section{Referências}

BARTHES, Roland. S/Z, Torino: Einaudi, 1981 , p. 139.

BORCES, J. L. Pierre Menard, autore del "Chisciotte”, In BORCES, J. L., Finzioni. Torino: Enaudi, 1971.

BRENDEL, F. Dr. Eduard Hanslick, Vom Musikalisch-Schönen."Neve Zeitschrift für Musik", XLII, n. 9, p. 90, 23 de fevereiro de 1855.

BUDEN, J. Le opere di Verdi, III, Da Don Carlos a Falstaff. Torino: EDT, 1988.

ECO, Umberto, Lector in fabula, Milano: Bompiani, 1995.

EGCEBRECHT, H. H. Sinn und Gehalt Aufsätze zur musikalischen Analyse, Wilhelmshaven, Heinrichschofen [1979]; In (trad. it. parcial) ECCEBRECHT, H. H., Il senso della musica, Bologna: il Mulino, 1987.

Senso e contenuto in musica, in ID., Musica in occidente. Dal Medioevo ad oggi. Scandicci (Firenze): La Nuova Italia, 1996.

GARDA, M. Musica sublime. Metamorfosi di unidea nel Settecento musicale. Milano-Lucca: Ricordi-LIM, 1995.

Topoi retorici ed ermeneutica musicale: un problema di metodo. In STEFANI, G.; TARASTI, E.; MARCONI L. (ed.). Musical Signification, Between Rhetoric and Pragmatics. In 5th INTERNATIONAL CONCRESS ON MUSICAL SICNIFICATION, Bologna, Proceedings of the $5^{\text {th }}$ International Congress on Musical Signification, Bolgona: CLUEB, 1998, p. 159-169: 160-161.

HANSLICK, Eduard. Vom Musikalisch-Schönen. Ein Beitrag zur Revision der Ästhetik der Tonkunst. Leipzig: Weigel, 1854 [reimpresso em Darmstadt: Wissenschaftliche Buchgedellschaft, 1991].

; DONA, M. (trad.). Il bello musicale, Milano: Minuziano,

1945 (nova edição Milano: Martello, 1971 ). 
HECEL, Georg Firedrich. Vorlesungen über die Ästhetik. In HECEL, Georg Firedrich. MOLDENHAUER E.; MICHAEL, K. M. (org.). Werke, , Frankfurt: Suhrkamp, XIII, 1986.

LUKÁCS, G.; PIANA, C (trad. italiana). Storia e coscienza di classe. Milano: Sugar, p. 94, 1967.

KELLER, H. K. 503: The unity of Contrasting Themes and Movements - 1, "Music Review”, 17, p. 48-49, 1956.

KIVY, Peter. The Fine Art of Repetition: Essays in the Philosophy of Music. Cambridge (Inglaterra): Cambridge University Press, 1993.

PAYZANT, G. Eduard Hanslick and Bernhard Gutt, "The Music Review", L, n. I, p. 124-133, 1989a;

Hanslick on music as product of feeling. "Journal of Musicological Research", 9, p. 133-167, $1989 \mathrm{~b}$.

ROSSI, L. E. Musica e psicologia nel mondo antico e nel mondo moderno. La teoria antica dell'ethos musicale e la moderna teoria degli affetti, in Synaulia. Cultura musicale in Crecia e contatti mediterranei, CASSIO, A. C.; MUSTI, D.; ROSSI L. E. (org.); In Qauderni dell'Istituto Universitario Orientale di Napoli, Sez. Filologico-letteraria, n. 5, p. 57-96: 88-89, 2000.

SCHMIDT, L. Arabeske. Zu einigen Voraussetzungen und Konsequenzen von Eduard Hanslicks muikalischen Formbegriff, "Archiv für Musikwissenschaft", XLVI, n. 2, p. 91-120, 1989;

STRAUSS, Dietmar. Eduard Hanslick: Vom Musikalisch-Schönen. Ein Beitrag zur Revision der Ästhetik in [sic] der Tonkunst, vol. I: Historischkeritsche Ausgabe, vol. II: Hanslicks Schrift in textkritischer Sicht, MainzLondon-New Yor-Paris-Tokio, Schott, 1990. 


\section{Sobre os autores}

Maurizio Giani nasceu em Grossetto, Itália, no ano de 1948, e estudou música efilosofia em Firenze. Fez seu doutorado na Universidade de Bologna em 1995, com tese sobre os escritos estéticos do jovem Richard Wagner. Foi professor de História da Música na Universidade de Salerno (Itália). É especialista nos aspectos dramatúrgicos da música de Wagner, na relação entre texto e música na obra de Robert Schumman, no pensamento de Thedor W. Adorno, e no wagnerianismo de d'Annunzio e Thomas Mann. Possui como principais publicações os livros Johannes Brahms (Palermo: L'Epos, 2011 ) e a nova tradução comentada feita a partir dos manuscritos e das modificações das três edições feitas pelo próprio autor de Oper und Drama de Richard Wagner (Opera e dramma, Astrolabio-Ubaldini, 2016). É violonista e professor de Estética Musical no Dipartimento di Arti da Universidade de Bologna (Itália).

Rafael Alexandre da Silva é natural de Ribeirão Preto, no interior de São Paulo. É compositor, flautista, regente e pesquisador. Tem Licenciatura em Música e Mestrado em Música pela Escola de Comunicações e Artes da Universidade de São Paulo. Atua como compositor e musicista em festivais dentro e fora do Brasil, tendo obras executadas inclusive nas últimas edições do Festival Música Nova "Gilberto Mendes". Atua como membro organizador do Festival "Fiato al Brasile", que é sediado em Ribeirão Preto e Faenza (Itália), e faz parte do corpo editorial da Revista da Tulha. É doutorando em Música (Composição Musical) pelo Departamento de Artes da Universidade Federal do Paraná, em Curitiba, sob orientação da compositora e Profa. Dra. Roseane Yampolschi, e, atualmente, realiza, com bolsa, um doutorado-sanduíche financiado pelo Programa de Doutorado-sanduíche no Exterior da CAPES/MEC (2017/2018) na Universidade de Bologna (Itália), sob a orientação do Prof. Dr. Maurizio Giani. 